\title{
Strategies for psychosocial risk management in manufacturing ${ }^{\text {tr }}$
}

\author{
José Guadix ${ }^{*}$, Jesús Carrillo-Castrillo ${ }^{1}$, Luis Onieva ${ }^{1}$, David Lucena ${ }^{1}$ \\ University of Seville, Camino Descubrimientos s/n, Isla Cartuja, 41092 Seville, Spain
}

\section{A R T I C L E I N F O}

\section{Article history:}

Received 26 January 2015

Received in revised form 30 January 2015

Accepted 5 February 2015

Available online xxxx

\section{Keywords:}

Strategy

Manufacturing

Business performance

Psychosocial risks

Health and safety management

Structural equation modeling

\begin{abstract}
A B S T R A C T
Psychosocial risk is a concern for employers across Europe. Psychosocial risk management, however, is younger than other risk management fields such as safety, hygiene, and ergonomics. Psychosocial risk control prevents accidents and absenteeism. This study examines strategies for psychosocial risk management in manufacturing organizations. The study employs structural equation modeling to analyze results of the European Survey of Enterprises on New and Emerging Risks (ESENER), a survey that fills an information gap concerning health and safety at work. The analysis yields three latent variables: psychosocial safety management, health and safety activities, and psychosocial performance. The study shows the benefits of adopting psychosocial safety management systems to improve psychosocial risk performance. Psychosocial preventive activities mediate the relationship between psychosocial safety management and psychosocial performance. Effective psychosocial risk management's benefits are so great that policymakers should specifically promote psychosocial risk management. Promoting psychosocial management systems and psychosocial preventive activities is likely to effectively improve overall psychosocial performance in European countries.
\end{abstract}

(c) 2015 Elsevier Inc. All rights reserved.

\section{Introduction}

Psychosocial risk is a concern for employers across Europe. The European Risk Observatory (European Agency for Safety and Health at Work, 2007) cites psychosocial risk as an emerging risk form. According to the European Risk Observatory's forecasts, five factors cause psychosocial risk: (i) employment contract forms and job insecurity, (ii) the aging workforce, (iii) work intensification, (iv) high emotional demands at work, and $(\mathrm{v})$ poor work-life balance.

The decision to dedicate the 2014 and 2015 Healthy Work Campaign to managing stress illustrates this issue's importance in Europe. Stress is the second most reported work-related health problem in Europe, and causes more than half of all lost working days in Europe. A campaign leaflet indicates that "managing stress and psychosocial risks can contribute to the delivery and improvement of key business performance indicators, such as meeting quality and delivery goals, becoming a more reliable supplier, lowering operating costs and reducing staff turnover" (Eurofound and EU-OSHA, 2014). As campaign supporting literature asserts, "Psychosocial factors are linked not only to health outcomes but also to performance-related outcomes such as absenteeism, work ability and especially job satisfaction" (Publications Office of the European Union, 2014).

\footnotetext{
is The authors are grateful for the contributions from Adolfo López, University of Valladolid, and Juan Carlos Rubio, University of Málaga, and for their careful reading and suggestions on revising this essay.

* Corresponding author. Tel.: + 34954486042.

E-mail addresses: guadix@us.es (J.Guadix),jesus.carrillo.castrillo@juntadeandalucia.es (J. Carrillo-Castrillo), onieva@us.es (L. Onieva), davidjlucena@gmail.com (D. Lucena).

${ }^{1}$ Tel.: + 34954486042 .
}

As part of human resource management, an innovative strategy in psychosocial risk management may increase organizational social capital by encouraging relationships among employees. Social capital denotes aggregate resources embedded in, available through, and obtained from an individual's or organization's relationships (Chuang, Chen, \& Chuang, 2013). Furthermore, improving social relationships between an organization's members enhances innovation (Maurer, Bartsch, \& Ebers, 2011).

Council Directive 89/391/EEC for the assessment and management of psychosocial risks and work-related stress establishes mandatory health and safety management guidelines within the European Union. Employers must evaluate all risks. Council Directive 89/391/EEC aims to improve occupational health and safety. The directive covers all sectors, both public and private, and all types of risk.

The directive states that the employer has a duty to address all types of risk to ensure workers' health and safety in every work-related aspect. Psychosocial risk management, however, is younger than other risk management fields such as safety, hygiene, and ergonomics. Managers should consider motivation, strategy, and perceived risks when deciding which health and safety management model to adopt (Carrillo, Guadix, \& Onieva, 2014).

Although psychosocial risks can cause injury and other health problems, very few reports cite psychosocial risks as causing such injury or illness. Therefore, to analyze psychosocial risk management performance, intermediate outcomes such as job satisfaction are useful. In addition, safety management is easier to evaluate by analyzing activities that control and prevent risks.

Most research on psychosocial risk focuses on how psychosocial risks affect health. In business strategy, psychosocial risks deeply 
Table 1

Descriptive statistics for the sample.

\begin{tabular}{llll}
\hline & Mean & SD & N \\
\hline MM155 & 1.22 & 0.45 & 28,649 \\
MM158 & 1.69 & 0.75 & 28,649 \\
MM159 & 2.13 & 0.89 & 28,649 \\
MM250 & 1.83 & 0.63 & 28,649 \\
MM251 & 0.73 & 28,649 \\
MM252 & 1.87 & 0.72 & 28,649 \\
MM302 & 1.95 & 0.54 & 28,649 \\
MM263 & 1.58 & 1.18 & 26,803 \\
MM266 & 2.42 & 0.61 & 26,803 \\
MM267 & 1.48 & 0.58 & 26,803 \\
ER308 & 1.39 & 0.48 & 7226 \\
ER309 & 1.71 & 0.43 & 7226 \\
ER310 & 1.79 & 0.32 & 7226 \\
\hline
\end{tabular}

concern managers because these risks affect workers' health. Scholars estimate at $40 \%$ the proportion of outcomes that directly relate to work environment differences (Labriola, Lund, \& Burr, 2006).

The demand-control-support model of the 1980s remains the standard for explaining which organizational variables affect workers' psychosocial states (Bakker \& Demerouti, 2007). The model comprises three main dimensions: job demands, latitude in job decisions, and social support at work. Kristensen (1995) and Rusli, Edimansyah, and Naing (2008) report that workers in jobs with high demands, low decision latitude, and low social support suffer from greater risk of poor psychological well-being.

Psychosocial risks therefore constitute an important area for managerial improvement within any organization. Psychosocial risk control prevents accidents and absenteeism. Strategically, organizations that manage psychosocial risks effectively can be more competitive. In addition, management involvement is influential in improving overall employee health at the organizational level (Oliver, Cheyne, Tomas, \& Cox, 2002). The main organizational outcomes are greater job satisfaction, lower absenteeism, and better productivity (Leka \& Cox, 2008).

Today, the psychosocial safety climate is an emerging construct that refers to shared perceptions regarding policies, practices, and procedures that protect workers' psychological health and safety. The construct of the psychosocial safety climate in organizations captures how well organizations manage job demands. In addition, the psychosocial safety climate correlates negatively with psychological health problems (Idris, Dollard, Coward, \& Dormann, 2012). Tools such as PSC-12 (Hall, Dollard, \& Coward, 2010) measure the psychosocial safety climate.

Management strategies should seek to improve the psychosocial safety climate as a step toward improving overall employee wellbeing. Increasing job support from managers and colleagues exemplifies such strategies (Dollard, Winefield, Winefield, \& de Jonge, 2000). In addition, worker representation can contribute to preventing psychosocial risks (Walters, 2011).

Thus, psychosocial risk management is important in human factors strategy. Buller and McEvoy (2012) discuss linkages between an organization's strategy, its human resources, and performance. According to Chuang et al. (2013), human resource practices that foster relationships between employers positively relate to organizational social capital. Psychosocial risk management thereby contributes to human factors management.

Psychosocial risk management needs specific tools. Leka, Jain, Widerszal-Bazyl, Zołnierczyk-Zreda, and Zwetsloot (2011) highlight the need for a psychosocial risk management standard. In a recent study, Bergh, Hinna, Leka, and Jain (2014) develop a psychosocial risk indicator. Such an indicator could represent a powerful tool in psychosocial risk management. First, however, the existing management system would have to adopt the indicator, and overall health and safety risk management processes would have to integrate the indicator.

Most organizations, however, insufficiently understand and incorporate psychosocial risks into strategic decision processes. The main barrier to understanding and incorporating such risks relates to practical difficulties in knowing how to successfully manage psychosocial risks (Langenham, Leka, \& Jain, 2013).

Stakeholders report organizations' inadequate adoption of Council Directive 89/391/EEC (Iavacoli et al., 2011). The current risk-prevention culture in the EU builds on the directive (Leka et al., 2011). However, despite several subsequent policies that contribute to psychosocial risk management in the EU, evaluation of initiatives in psychosocial policies highlights areas for improvement in psychosocial risk management.

Official inspection bodies traditionally treat psychosocial hazards as a marginal issue (Johnstone, Quinlan, \& McNamara, 2011). Hence, managers tend to focus less on psychosocial risks than on physical and hygiene hazards. Now, regulators' focus on psychosocial risks is increasing. Enforcement seems an ineffective approach, however. Failure in a 2001-2003 project by the Swedish Work Environment Authority to improve methods for psychosocial risk inspection at work exemplifies this ineffectiveness (Bruhn \& Frick, 2011).

Preventing psychosocial risks at work should concern organizations because these risks influence internal and external outcomes, while threatening workers' health and safety. Furthermore, preventing psychosocial risk affords top management an opportunity to gain competing advantage. Accordingly, the psychosocial risk management strategy is an important matter.

This study explores the mechanisms that link managers' motivation to undertake psychosocial safety management procedures with wellperformed activities. The study also examines how organizational issues explain organizations' psychosocial risk management performance.

Table 2

Correlation matrix.

\begin{tabular}{|c|c|c|c|c|c|c|c|c|c|c|c|c|c|}
\hline Variables & MM155 & MM158T & MM159T & MM250 & MM251 & MM252 & MM302 & MM263L & MM266_1 & MM267_1 & ER308 & ER309 & ER310 \\
\hline MM155 & - & $.17^{* *}$ & $.17^{* *}$ & $.13^{* *}$ & $.17^{* *}$ & $.11^{* *}$ & $.15^{\text {** }}$ & $.06^{* *}$ & $.07^{* *}$ & $.07^{* *}$ & $.05^{* *}$ & .03 & .02 \\
\hline MM158T & & - & $.25^{* *}$ & $.08^{* *}$ & $.07^{* *}$ & $.05^{*}$ & $.11^{\text {** }}$ & $.05^{*}$ & $.05^{* *}$ & $.08^{* *}$ & .04 & .04 & .03 \\
\hline MM159T & & & - & $.07^{* *}$ & $.08^{* *}$ & $.08^{* *}$ & $.11^{* *}$ & $.11^{* *}$ & $.09^{* *}$ & $.13^{* *}$ & $.05^{*}$ & .01 & .02 \\
\hline MM250 & & & & - & $.47^{* *}$ & $.38^{* *}$ & $.30^{* *}$ & $.16^{* *}$ & $.22^{* *}$ & $.19^{* *}$ & $.12^{* *}$ & $.14^{* *}$ & $.05^{*}$ \\
\hline MM251 & & & & & - & $.64^{* *}$ & $.26^{* *}$ & $.14^{* *}$ & $.15^{* *}$ & $.12^{* *}$ & $.16^{* *}$ & $.21^{* *}$ & $.06^{* *}$ \\
\hline MM252 & & & & & & - & $.19^{* *}$ & $.16^{* *}$ & $.16^{* *}$ & $.14^{* *}$ & $.11^{* *}$ & $.16^{* *}$ & $.07^{* *}$ \\
\hline MM302 & & & & & & & - & $.19^{* *}$ & $.29^{* *}$ & $.25^{* *}$ & $.12^{* *}$ & $.07^{* *}$ & .01 \\
\hline MM263L & & & & & & & & - & $.41^{* *}$ & $.39^{* *}$ & .02 & $.06^{* *}$ & .04 \\
\hline MM266_1 & & & & & & & & & - & $.51^{* *}$ & $.08^{* *}$ & $.06^{* *}$ & $.04^{*}$ \\
\hline MM267_1 & & & & & & & & & & - & $.08^{* *}$ & $.07^{* *}$ & .03 \\
\hline ER308 & & & & & & & & & & & - & $.41^{* *}$ & $.23^{* *}$ \\
\hline ER309 & & & & & & & & & & & & - & $.33^{* *}$ \\
\hline ER310 & & & & & & & & & & & & & - \\
\hline
\end{tabular}

** Correlation significant at 0.01 level.

* Correlation significant at 0.05 level. 
Table 3

Factor analysis.

\begin{tabular}{llrr}
\hline & \multicolumn{2}{l}{ Components } \\
\cline { 2 - 4 } & 1 & 2 & 3 \\
\hline MM155 & .21 & -.01 & .10 \\
MM158T & .12 & .04 & .09 \\
MM159T & .17 & .09 & .05 \\
MM250 & .66 & -.12 & .39 \\
MM251 & .81 & -.39 & -.06 \\
MM252 & .77 & -.36 & -.31 \\
MM263L & .47 & .69 & -.41 \\
MM266_1 & .48 & .60 & .17 \\
MM267_1 & .43 & .58 & .17 \\
MM302 & .47 & .18 & .47 \\
ER308 & .22 & -.05 & .37 \\
ER309 & .26 & -.09 & .21 \\
ER310 & .10 & -.02 & .09 \\
\hline
\end{tabular}

The OSH_psycho composite score measures the number of practices organizations use to manage psychosocial risk. According to the European Agency for Safety and Health at Work (2012), OSH_psycho scores show that manufacturing is the industry with the poorest performance in Europe. The OSH_psycho composite score also depends on organization size and country. Furthermore, the OSH_psycho composite score depends on organizations' preventive activities and safety management systems. The European Agency for Safety and Health at Work (2012) reports links between organizational risk management, preventive activities, and performance. Therefore, this research tests three hypotheses.

H1. Psychosocial preventive activities positively affect organizations' psychosocial performance.

H2. Psychosocial safety management positively affects organizations' psychosocial performance.

H3. Psychosocial safety management positively affects psychosocial preventive activities.

\section{Materials and methods}

This study analyzes data from the 2009 European Survey of Enterprises on New and Emerging Risks (ESENER). ESENER does not collect data at the worker level. At the worker level, most surveys measure job contents and organizational support. ESENER collects data at the organizational level, consistent with this study's scope. At the organizational level, information about manager motivation and risk management is more important than information about workers.

\subsection{ESENER: a European survey}

ESENER fills an information gap regarding health and safety at work. Although other sources provide information (Dollard, Skinner, Tuckey, \& Bailey, 2007) on work-related accidents and illnesses, these sources provide little information on how organizations manage health and safety risks in practice, especially psychosocial risks (European Agency for Safety and Health at Work, 2010). ESENER provides the most detail on organizations. ESENER focuses on health and safety management and preventive measures such as risk assessment, management's commitment to health and safety, and sources of expertise, advice, and information.

ESENER also collects data on the main reasons for addressing health and safety, psychosocial risks, major difficulties in dealing with these issues, and the role of worker participation. The statistical population comprises all organizations with 10 or more employees in 31 participating countries, including all EU Member States. ESENER covers most industries, and collects data from around 36,000 interviews.

In each organization, the respondent is the highest-ranking manager responsible for health and safety at work. In organizations where a formally designated representative takes specific responsibility for workers' health and safety, a second interview with this representative collects additional data. Management grants permission for interviews.

Consistent with its scope, this research considers only answers from manufacturing organizations. Sample stratification uses a matrix of two industries (production industries and services) and five size groups (10-19, 20-49, 50-199, 200-499, and 500+ employees).

\subsection{Structural equation modeling}

Structural equation modeling (SEM) is a common method for analyzing complex models with direct and indirect variables. Using path analysis, SEM expands upon traditional statistical methods by simultaneously testing predictive variables' direct and indirect effects (Kline, 2010). AMOS version 22.0 tests hypotheses (Byrne, 2001).

SEM has three major functions (Chiu, 2003): hypothesis testing, structural confirmatory and modeling analysis, and comparison. Thus, SEM is a suitable tool to investigate latent psychosocial risk variables and fit overall interrelationships. Model fit tests (Hsu et al., 2012; Schermelleh-Engel, Moosbrugger, \& Muller, 2003) such as the relative chi square $\left(\chi^{2} /\right.$ d.f.), comparative fit index (CFI), normal fit index (NFI), Tucker Lewis index (TLI) and root mean square error of approximation (RMSEA) evaluate the model's fit.

Psychosocial risk and safety constructs are difficult to measure at the organizational level. Studies show that constructs' internal validity is especially low. Larsson, Pousette, and Törner (2008) use the construct of workplace commitment (Cronbach's alpha $=0.58$ ), and AmponsahTawiah, Leka, Jain, Hollis, and Cox (2014) use the construct of ambient conditions (Cronbach's alpha $=0.56$ ). According to Al-Refaie (2013), Cronbach's alpha of around 0.6 is sufficient for studies of this kind.

The first step is to explore variable (factor) loadings on the latent constructs. To complete this process, Al-Refaie (2013) advocates using descriptive statistics (Table 1), correlation between items (Table 2), and factor analysis (Table 3).

The next step is to incorporate relationships between constructs and test the model's overall goodness of fit. Using ESENER data, SEM tests the hypotheses for three country groups: all 31 countries, 11 northern European countries, and 4 southern European countries. To ensure

Table 4

Psychosocial safety management: factor loadings of each item in the construct.

\begin{tabular}{|c|c|c|c|c|}
\hline Question & Description & $\begin{array}{l}\text { All } \\
\text { countries }\end{array}$ & $\begin{array}{l}\text { Northern } \\
\text { countries }\end{array}$ & $\begin{array}{l}\text { Southern } \\
\text { countries }\end{array}$ \\
\hline MM155 & Is there a documented policy, established management system, or action plan on health and safety in your establishment? & 0.65 & 0.67 & 0.63 \\
\hline MM158T & Are health and safety issues raised in high-level management meetings regularly, occasionally or practically never? & 0.66 & 0.67 & 0.65 \\
\hline MM159T & Is there a high degree of line manager and supervisor involvement in health and safety management? & 0.67 & 0.66 & 0.65 \\
\hline MM250 & Does your establishment have a procedure to deal with work-related stress? & 0.58 & 0.58 & 0.56 \\
\hline MM251 & Is there a procedure in place to deal with bullying or harassment? & 0.53 & 0.55 & 0.49 \\
\hline MM252 & And do you have a procedure to deal with work-related violence? & 0.56 & 0.61 & 0.45 \\
\hline MM302 & Have you used information or support from external sources on how to deal with psychosocial risks at work? & 0.63 & 0.63 & 0.61 \\
\hline \multicolumn{2}{|c|}{ Cronbach's alpha } & 0.66 & 0.66 & 0.63 \\
\hline
\end{tabular}


Table 5

Psychosocial preventive activities: factor loadings of each item in the construct.

\begin{tabular}{|c|c|c|c|c|}
\hline Question & Description & All countries & Northern countries & Southern countries \\
\hline MM263L & The measures taken to manage psychosocial risks are effective? & 0.68 & 0.63 & 0.58 \\
\hline MM266_1 & Have employees been consulted regarding measures to deal with psychosocial risks? & 0.55 & 0.50 & 0.56 \\
\hline MM267_1 & Are employees encouraged to participate actively in the implementation and evaluation of the measures? & 0.58 & 0.58 & 0.46 \\
\hline Cronbach's & alpha & 0.69 & 0.67 & 0.63 \\
\hline
\end{tabular}

Table 6

Psychosocial performance: factor loadings of each item in the construct.

\begin{tabular}{|c|c|c|c|c|}
\hline Question & Description & All countries & Northern countries & Southern countries \\
\hline ER308 & In the last 3 years, have you received requests concerning stress? & 0.44 & 0.35 & 0.52 \\
\hline ER309 & In the last 3 years, have you received requests to tackle bullying or harassment? & 0.31 & 0.26 & 0.33 \\
\hline ER310 & In the last 3 years, have you received requests to tackle workplace violence? & 0.58 & 0.59 & 0.51 \\
\hline \multicolumn{2}{|c|}{ Cronbach's alpha } & 0.57 & 0.54 & 0.55 \\
\hline
\end{tabular}

comparability, the model is the same for all country groups. Northern European countries are Austria, Belgium, Denmark, Finland, France, Germany, Ireland, Luxembourg, the Netherlands, Sweden, and the United Kingdom. Southern countries are Greece, Italy, Portugal, and Spain. ESENER covers 2357 manufacturing organizations across all 31 countries: 1207 in northern European and 376 in southern European countries.

\section{Results}

Analysis yields three latent variables: psychosocial safety management, health and safety activities, and psychosocial performance. Reports by the European Agency for Safety and Health at Work drawing on data from ESENER (European Agency for Safety and Health at Work, 2012) identify observed variable loadings on the latent variables.

The construct of psychosocial safety management accounts for questions relating to specific safety management procedures and practices (Table 4). Overall reliability within the three country groups is approximately 0.7. Managers' answers include responses to all these questions.

The construct of health and safety activities includes questions that relate to specific activities regarding psychosocial risks (Table 5). Overall reliability within the three country groups is less than 0.45 . Managers' answers include responses to all these questions.

The construct of psychosocial performance includes questions relating to psychosocial risk management outcome according to the answers of the workers' representatives (Table 6). Overall reliability within the three country groups is greater than 0.5 .

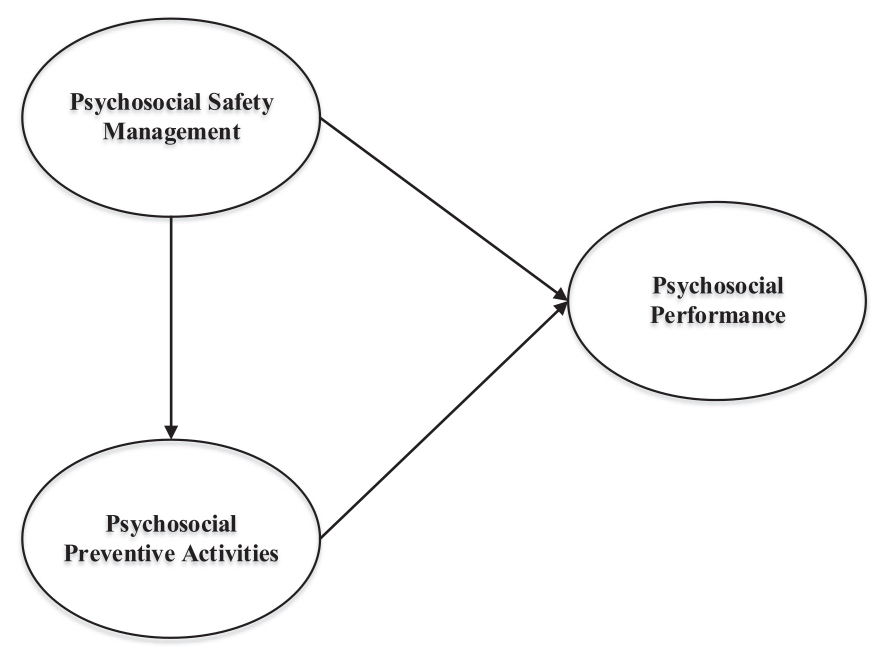

Fig. 1. Regression model to assess relationships between latent variables.
A structural equation regression model tests relationships between latent variables (Fig. 1).

The structural equation model describes paths between the three latent variables. Table 7 shows estimated regression weights. Table 8 shows model fit indicators.

\section{Discussion}

The model's overall fit is acceptable, according to thresholds that appear in the literature (Hsu et al., 2012; Kline, 2010). Most health and safety structural equation models are difficult to fit because of unobserved variables outside ESENER's scope. Such variables include safety or psychosocial climate. In this study, overall fit is sufficient for testing research hypotheses.

In the present study, psychosocial preventive activities mediate the relationship between psychosocial safety management and psychosocial performance. Furthermore, the effect of psychosocial activities on psychosocial performance in the manufacturing industry is nonsignificant. One feasible explanation is that preventive activities fail to manage psychosocial risk effectively, whereas psychosocial safety management is effective.

Therefore, according to ESENER data, organizations can use psychosocial performance to improve psychosocial safety management in manufacturing. This finding supports Leka et al.'s (2011) proposals concerning psychosocial safety management's importance in psychosocial risk management. In addition, specific psychosocial safety management can be an effective strategic decision if top management wants to maximize the benefits of psychosocial risk control. In addition, risk management is insufficient to deal with psychosocial risks (Langenham et al., 2013).

A management system is a network of elements that interrelate. These elements include responsibilities, authorities, relationships, functions, activities, processes, practices, procedures, and resources. A management system uses these elements to establish policies, plans, programs, and objectives (Carrillo et al., 2014).

At the regional or national levels, results suggest that if policymakers can understand managers' decisions to implement psychosocial management systems, policymakers can promote improvement in psychosocial performance.

Recent research shows how regulation and stakeholder pressure can positively affect the implementation of occupational safety management systems (Chen \& Zorigt, 2013). Thus, this study's findings reveal a feasible way of improving overall risk management.

Strategically, improving management systems helps other manufacturing challenges such as innovation (Ribeiro Soriano, 2010). Integrating different management systems such as quality, safety, and environmental systems is another strategic decision that can provide 
Table 7

Regression coefficients of the model.

\begin{tabular}{|c|c|c|c|}
\hline Regression paths & All countries & Northern countries & Southern countries \\
\hline Psychosocial preventive activities $\leftarrow$ psychosocial safety management & 0.32 & 0.40 & 0.14 \\
\hline Outcome $\leftarrow$ psychosocial safety management & 0.30 & 0.26 & 0.13 \\
\hline Outcome $\leftarrow$ psychosocial preventive activities & $0.04^{\mathrm{a}}$ & $0.00^{\mathrm{a}}$ & $0.10^{\mathrm{a}}$ \\
\hline Cronbach's alpha & 0.71 & 0.70 & 0.65 \\
\hline
\end{tabular}

a Non-significant.

competitive advantage. Thus, developing an international standard is necessary (Abad, Rodríguez, \& Llimona, 2002).

Results show that ESENER questions regarding the activities of organizations do not cover psychosocial performance. Other activities resulting from safety management could explain how manufacturing organizations cope with psychosocial risks. Such items include human factors management (Chuang et al., 2013) and knowledge management (Chen, Huang, \& Hsiao, 2010).

Future ESENER surveys should include questions that more broadly assess how managers deal with human factors. Psychosocial performance measures in the current questionnaire lack key latent constructs such as the psychosocial safety climate (Hall et al., 2010).

Results differ depending on country profile. Regression path coefficients are higher in northern European countries, thus implying a stronger effect of psychosocial management systems on psychosocial performance. Likewise, psychosocial management systems affect psychosocial activities more in northern European countries than in southern European countries.

Factor loadings of questions in the latent construct of psychosocial safety management are higher for northern European countries. One possible explanation for these differences is that ESENER may be missing questions that can help explain how southern European countries manage risks. For instance, results reveal significant differences between Sweden's (northern Europe) and Spain's (southern Europe) occupational risk management (Morillas, Rubio-Romero, \& Fuertes, 2013). The model lacks information to provide possible explanations for these differences, but cultural differences between northern and southern European countries constitute a hypothesis that future research should test.

\section{Conclusions}

The most important strategic action regarding psychosocial risks in the European manufacturing industry is to implement an effective psychosocial safety management system. Developing an international standard, promoting the adoption of psychosocial safety management systems, and performing audits can help managers improve organizations' social capital. Effective psychosocial risk management yields benefits so important that policymakers should promote psychosocial safety management. This promotion should rely on scientific research. Accordingly, this study shows that promoting psychosocial management systems and psychosocial preventive activities is likely to effectively improve overall psychosocial performance in European countries.

ESENER is a useful tool to research psychosocial risk management, at least at the organizational level. Nevertheless, incorporating complementary questions regarding psychosocial climate and issues

Table 8

Model fit indicators.

\begin{tabular}{llll}
\hline & All countries & Northern countries & Southern countries \\
\hline$\chi^{2} /$ d.f. $(<3)$ & 1.28 & 1.30 & 0.97 \\
CFI $(>0.9)$ & 1.00 & 0.99 & 1.00 \\
NFI $(>0.9)$ & 0.99 & 0.97 & 0.95 \\
TLI $(>0.9)$ & 1.00 & 0.99 & 1.00 \\
RMSEA $(<0.08)$ & 0.01 & 0.02 & 0.00
\end{tabular}

concerning the management decision process would yield a better understanding of psychosocial risk management.

\section{References}

Abad, J., Rodríguez, P.M., \& Llimona, J. (2002). Towards an international standard on occupational health and safety management. International Journal of Occupational Safety and Ergonomics, 8(3), 309-319.

Al-Refaie, A. (2013). Factors affect companies' safety performance in Jordan using structural equation modelling. Safety Science, 57, 169-178.

Amponsah-Tawiah, K., Leka, S. Jain, A., Hollis, D., \& Cox, T. (2014). The impact of physical and psychosocial risks on employee well-being and quality of life: The case of the mining industry in Ghana. Safety Science, 65, 28-35.

Bakker, A.B., \& Demerouti, E. (2007). The Job Demands-Resources model: State of the art. Journal of Managerial Psychology, 22(3), 309-328.

Bergh, L.I.V., Hinna, S., Leka, S., \& Jain, A. (2014). Developing a performance indicator for psychosocial risk in the oil and gas industry. Safety Science, 62, 98-106.

Bruhn, A. \& Frick, K. (2011). Why it was so difficult to develop new methods to inspect work organization and psychosocial risks in Sweden. Safety Science, 49(4), 575-581.

Buller, P.F., \& McEvoy, G.M. (2012). Strategy, human resource management and performance: Sharpening line of sight. Human Resource Management Review, 22, 43-56.

Byrne, B.M. (2001). Structural equation modeling with AMOS: Basic concepts, applications, and programming. London: Routledge.

Carrillo, J.A., Guadix, J., \& Onieva, L. (2014). Safety management models in manufacturing companies. In J.C. Prado-Prado, \& J. García-Arca (Eds.), Annals of industrial engineering 2012 (pp. 299-306). London: Springer

Chen, C. -J., Huang, J. -W., \& Hsiao, Y. -C. (2010). Knowledge management and innovativeness: The role of organizational climate and structure. International Journal of Manpower, 31(8), 848-870.

Chen, J.K.C., \& Zorigt, D. (2013). Managing occupational health and safety in the mining industry. Journal of Business Research, 66, 2321-2331.

Chiu, H.C. (2003). The theory, technology, and application of the structural equation modelLISREL. Taipei (Taiwan): Yeh Yeh Book Gallery.

Chuang, C.H., Chen, S. -J., \& Chuang, C. -W. (2013). Human resource management practices and organizational social capital: The role of industrial characteristics. Journal of Business Research, 66(5), 678-687.

Dollard, M., Skinner, N., Tuckey, M.R., \& Bailey, T. (2007). National surveillance of psychosocial risk factors in the workplace: An international overview. Work and Stress, 21(1), 1-29.

Dollard, M.F., Winefield, H.R., Winefield, A.H., \& de Jonge, J. (2000). Psychosocial job strain and productivity in human service workers: A test of the demand-control-support model. Journal of Occupational and Organizational Psychology, 73(4), 501-510.

Eurofound and EU-OSHA (2014). Psychosocial risks in Europe: Prevalence and strategies for prevention. Luxembourg: Publications Office of the European Union.

European Agency for Safety and Health at Work (2007). Expert forecast on emerging psychosocial risks related to occupational safety and health. Luxembourg: Office for Official Publications of the European Communities.

European Agency for Safety and Health at Work (2010). European Survey of Enterprises on New and Emerging Risks managing safety and health at work. Luxembourg: Publications Office of the European Union.

European Agency for Safety and Health at Work (2012). Management of psychosocial risks at work - An analysis of the findings of the ESENER - Technical report annexes 1 and 2. Luxembourg: Publications Office of the European Union.

Hall, G.B., Dollard, M.F., \& Coward, J. (2010). Psychosocial safety climate: Development of the PSC-12. International Journal of Stress Management, 17(4), 353-383.

Hsu, I. -Y., Su, T. -S., Kao, Ch. -S., Shu, Y. -L., Lin, P. -R., \& Tseng, J. -M. (2012). Analysis of business safety performance by structural equation models. Safety Science, 50(1), 1-11.

Iavacoli, S., Natali, E., Deitinger, P., Rondinone, B.M., Ertel, M., Jain, A., et al. (2011). Occupational health and safety policy and psychosocial risks in Europe: The role of stakeholders' perceptions. Health Policy, 101, 87-94.

Idris, M.A., Dollard, M.F., Coward, J., \& Dormann, C. (2012). Psychosocial safety climate: Conceptual distinctiveness and effect on job demands and worker psychological health. Safety Science, 50(1), 19-28.

Johnstone, R., Quinlan, M., \& McNamara, M. (2011). OHS inspectors and psychosocial risk factors: Evidence from Australia. Safety Science, 49(4), 547-557.

Kline, R.B. (2010). Principles and practice of structural equation modeling. New York: The Guilford Press.

Kristensen, T.S. (1995). The demand-control-support model: Methodological challenges for future research. Stress Medicine, 11(1), 17-26.

Labriola, M., Lund, T., \& Burr, H. (2006). Prospective study of physical and psychosocial risk factors for sickness absence. Occupational Medicine, 56(7), 469-474. 
Langenham, M.K., Leka, S., \& Jain, A. (2013). Psychosocial risks: Is risk management strategic enough in business and policy making? Safety and Health at Work, 4 , 87-94.

Larsson, S., Pousette, A., \& Törner, M. (2008). Psychological climate and safety in the construction industry-mediated influence on safety behaviour. Safety Science, 46, 405-412.

Leka, S., \& Cox, T. (2008). The European framework for psychosocial risk management: PRIMA-EF. UK: Institute of Work, Health and Organizations.

Leka, S., Jain, A., Widerszal-Bazyl, M., Zołnierczyk-Zreda, D., \& Zwetsloot, G. (2011). Developing a standard for psychosocial risk management: PAS 1010. Safety Science, 49(7), 1047-1057.

Maurer, I., Bartsch, V., \& Ebers, M. (2011). The value of intra-organizational social capital: How it fosters knowledge transfer, innovation performance, and growth. Organization Studies, 32(2), 157-185.

Morillas, R.M., Rubio-Romero, J.C., \& Fuertes, A. (2013). A comparative analysis of occupational health and safety risk prevention practices in Sweden and Spain. Journal of Safety Research, 47, 57-65.
Oliver, A., Cheyne, A., Tomas, J.M., \& Cox, S. (2002). The effects of organizational and individual factors on occupational accidents. Journal of Occupational and Organizational Psychology, 75(4), 473-488.

Publications Office of the European Union (2014). Psychosocial risks in Europe: Prevalence and strategies for prevention (A joint report from the European Foundation for the Improvement of Living and Working Conditions and the European Agency for Safety and Health at Work). Luxembourg: Publications Office of the European Union.

Ribeiro Soriano, D. (2010). Management factors affecting the performance of technology firms. Journal of Business Research, 63(5), 463-470.

Rusli, B.N., Edimansyah, B.A., \& Naing, L. (2008). Working conditions, self-perceived stress, anxiety, depression and quality of life: A structural equation modelling approach. BMC Public Health, 48(8).

Schermelleh-Engel, K., Moosbrugger, H., \& Muller, H. (2003). Evaluating the fit of structural equation models: Tests of significance and descriptive goodness-of-fit measures. Methods of Psychological Research Online, 8, 23-74.

Walters, W. (2011). Worker representation and psycho-social risks: A problematic relationship? Safety Science, 49(4), 599-606. 